\title{
Effect of sugar and jaggery on the quality characteristics of papaya leather and shelf life stability at room temperature
}

\author{
Servesh Kumar' ${ }^{1}$ Vishal Kumar ${ }^{2}$ and Chandra Prakash ${ }^{1}$ \\ ${ }^{1}$ B.F.I.T. Group of Institution, Dehradun (Uttarakhand) \\ ${ }^{2}$ Department of Agric. Engg. and Food Technology, SVPUAT, Meerut (U.P.)
}

\begin{abstract}
The quality attributes comprised of moisture content, acidity, $\mathrm{pH}$, optical density, TSS, total plate count. The quality parameters were done for fresh as well as stored papaya leather at $0,15,30,45$ and 60 days of storage under the room temperature and samples were packed in PET jars and glass jars. The TSS, pH, optical density and total plate count of papaya leather increased with increase of sugar and jaggery ratio at room temperature condition. The acidity and moisture content decreased with decrease in the level of papaya ratio and acidity values after 60 days of storage were observed the acidity $T_{1} 0.353, T_{2} 0.349, T_{3} 0.333, T_{4} 0.322$ and $T_{5} 0.367$ for the sample stored in pet jar and $T_{1} 0.348, T_{2} 0.360, T_{3} 0.350, T_{4} 0.333$ and $T_{5} 0.359$ for the sample stored in glass jar at room temperature. The moisture content of sample pet jar $\mathrm{T}_{1} 16.9, \mathrm{~T}_{2} 15.5, \mathrm{~T}_{3} 16.7, \mathrm{~T}_{4} 17.0$ and $\mathrm{T}_{5} 16.4$ and samples of glass jar $\mathrm{T}_{1} 16.7, \mathrm{~T}_{2} 16.3, \mathrm{~T}_{3} 16.0, \mathrm{~T}_{4} 17.0$ and $\mathrm{T}_{5} 16.1$ after 60 days at room temperature condition. The maximum overall acceptability score for the papaya leather prepared with sugar and jaggery ratio samples $\mathrm{T}_{1}$ 7.1 in glass jar and the minimum score $\mathrm{T}_{1} 6.8$ in pet jar at room temperature. It was concluded that papaya leather prepared with sugar and jaggery ratio of $\mathrm{T} 1, \mathrm{~T} 2$, and $\mathrm{T} 3$ samples was found to be superior of glass jar as compared to other samples.
\end{abstract}

Key words: Moisture content, TSS, Acidity, Optical density, pH, Total plate count, Sensory.

Fruit bar also called as leather or fruit slab, are confection product prepared from fruit pulps like, mango guava, papaya etc., papaya bar is the most commercially successful product in India. Today, foods are not only intended to satisfy hunger and necessary nutrients for humans but also to prevent nutrition-related diseases and improve physical and mental well- being of the consumers. In this regard, functional foods play an outstanding role. In the last decades, consumer demands in the field of food production have changed considerably. Carica papaya (family caricaceae) originated in Central America. Papaya is climatic fruit (Selvaraj etal., 1982). Papaya, papaw or pawpaw (Caricapapaya) is cultivated throughout the tropics for its fruit (Purseglove, 1968). The fruit are eaten green or ripe, fresh or in salad. They are also used for making juice, jam, crystallized fruits, candy and leather. Consumers more and more believe that foods contribute directly to their health.
Papaya (Carica papaya $L$ ) is an important fruit of India. Papaya fruits are called protective foods because of their nutritive contributions such as vitamins, minerals, bulk cellulose and prospecting. Fruits are generally liked by majority of the people from all age groups. But fruits are available only during specific season. There are many ways of preserving fruits and making fruit bars is one such method. Consumption of fruits is very important as they are nutritious and supply vitamins and minerals. Pulpy fruits like banana, mango, guava, apple etc. are best suited for making fruit bars. Assam and nearby states of North-East region produce many fresh fruits round the year and thus availability of the all-important raw material shall not be a problem. This product can also be manufactured in some other states like Uttaranchal, Punjab, UP, Maharashtra and soon. Chemical changes during the post harvest ripening of papaya have been reported by Chan (1978). 
Papaya is usually harvested when it shows signs of maturity; evident as skin slightly turning to yellow. Organic papayas generally left to ripen on the tree; however, care should be taken since overripen fruits actually fall off themselves and spoiled. In the store, papayas come in various sizes and maturity; therefore, select the one based on the serving size and timing. Choose the one with intact skin without any bruises or cuts. Unripe fruits can be kept at room temperature for few days but ripen ones should be stored in the refrigerator.

\section{Materials and Methods}

Preparation of papaya leather:The fully riped papaya was wash with fresh water and peeled than after extract pulp is done using electronic juicer for $15 \mathrm{~min}$. thereafter These samples are prepared with sweeteners ratio and papaya fruit the sample details as $T_{1}$ sample prepared papaya pulp with sugar (650 $\mathrm{gm}), \mathrm{T}_{2}$ sample prepared papaya pulp with sugar (450 gm), $\mathrm{T}_{3}$ sample prepared papaya pulp with jaggery (650 gm), $T_{4}$ sample prepared papaya pulp with jaggery $(450 \mathrm{gm})$ and $\mathrm{T}_{5}$ sample prepared papaya pulp with sugar, jaggery, then after completed this process, mixed the citric acid level $(0.3 \%)$. After those smearing stainless steel trays with desi ghee and mixture is poured in to the stainless steel trays. After spreading the mixture in to the trays, the trays were then placed in the hot air oven at $65^{\circ} \mathrm{C}$ for 58 hours, than after 58 hours the trays are taken out, cooled and leather is cut in to rectangular $(4.0 \times 4.0 \times 1.0 \mathrm{~cm})$ and packed in to pet jars and glass jars at room temperature.

\section{Evaluation of physico-chemical analysis of leather}

Total soluble solid: A drop of sample was placed on the prism and the observation was taken in front of sun light. The visible scale showed a dark line indication measuring TSS in degree ${ }^{\circ}$ Brix.

Acidity: $5 \mathrm{ml}$ sample was placed in $100 \mathrm{ml}$ distilled water, placed for heating for some period and a shake well and filtrate. Filtrate volume of aliquot was taken and titrated with $0.1 \mathrm{~N} \mathrm{NaOH}$ using phenolphthalein as indicator. The endpoint was denoted by the appearance of pink colour. The titration was repeated thrice and the average value was recorded (Srivastava and Kumar, 1994).

$$
\% \text { Acidity }=\frac{\text { Titre } \times 0.1 \times 0.064 \times 100}{\text { Wt. of sample taken } \times 1000}
$$

pH: $\mathrm{pH}$ is the measurement of the logarithm of inverse of hydrogen ion concentration in the solution.

Where,

$$
\mathbf{p H}=-\log \left(\mathbf{H}^{+}\right)
$$

$\left(\mathrm{H}^{+}\right)=$hydrogen ion concentration $(\mathrm{g} \backslash \mathrm{lit})$

The electronic $\mathrm{pH}$ meter was calibrated using $7 \mathrm{pH}$ and $4 \mathrm{pH}$ standard buffer solutions. Then electrode was dipped in the test solution and the temperature knob was adjusted to temperature of test solution. The function selector switch was set to $\mathrm{pH}$ and reading of digital display was allowed to stabilize.

Ascorbic Acid Estimation (Vitamin C): Samples of papaya leather were analyzed for the ascorbic acid content using 2.6- dichlorophenol indophenols titrimetrically as per the modified procedure of (Srivastava and Kumar, 1994).

$$
\begin{aligned}
& \text { Ascorbic acid } \quad 0.5 \mathrm{mg} \mathrm{x} \mathrm{V} \times 100 \mathrm{ml} \\
& (\mathrm{mg} / 100 \mathrm{~g})=\overline{\mathrm{V}_{1} \mathrm{ml} \mathrm{x} 15 \mathrm{ml} \times \mathrm{wt} \text {. of sample }}
\end{aligned}
$$

Optical Density: Optical density is the measurement of light that is absorbed by any material when a beam of monochromatic light incident on it. According to Beer's Law the intensity of a beam of monochromatic light decreases exponentially as the concentration of absorbing substance increases. Mathematically, O.D. of the medium is given by formula, Where,

$$
\text { Optical density }=\log \frac{I_{0}}{I_{t}}
$$

$\mathbf{I}_{0}=$ Intensity of the incident light

$\mathbf{I}_{\mathbf{t}}=$ Intensity of light transmitted through

the medium. 
Microbial Analysis: Microbial analysis was done to determine the Total Plate Count (TPC) of the sample on Nutrient Agar media for bacterial count as method recommended by (Harrigan and $\mathrm{Mc}$ Cance, 1966).

\section{Results and Discussion}

Effect on moisture content: The different compositions of sugar and jaggery and papaya extract pulp ratio with respect to change in moisture content (\%) during storage are given in Table 1.It is clear that the moisture content $(\%)$ of samples decreased in storage periods at room temperature. The moisture content of sample pet jar $\mathrm{T}_{1} 16.9, \mathrm{~T}_{2}$ 15.5, $\mathrm{T}_{3}$ 16.7, $\mathrm{T}_{4} 17.0$ and $\mathrm{T}_{5} 16.4$ and samples of glass jar $T_{1} 16.7, T_{2} 16.3, T_{3} 16.0, T_{4} 17.0$ and $T_{5}$ 16.1 after 60 days at room temperature condition. The moisture content decreased with increase as the ambient temperature condition. The lowest moisture content of the sample $T_{2} 15.5$ in pet jar and $T_{3} \quad 16.0$ in glass jar samples after 60 days storage periods.

Effect on TSS:It is clear that the TSS $\left({ }^{0}\right.$ Brix) of samples increased with increase in storage periods at room temperature in Table 1 . The combined effect of composition and storage period were also significant. The study also revealed that TSS $\left({ }^{0} \mathrm{Brix}\right)$ increased with increase in storage period irrespective of storage conditions. The increase in TSS ( ${ }^{0}$ Brix) could be due to the degradation of polysaccharides during storage in to soluble compounds (Mehta and Bajaj 1969; Singh et al.,2004). The TSS ( $\left.{ }^{0} \mathrm{Brix}\right)$ increases with increased in storage periods respectively of level of sugar and jaggery on storage temperature. The TSS value after 60 days storage were observed $\mathrm{T}_{1} 65.33, \mathrm{~T}_{2}$ $65.99, \mathrm{~T}_{3} 65.15, \mathrm{~T}_{4} 71.15$ and $\mathrm{T}_{5} 66.66^{\circ}$ brix for the pet jar sample and $\mathrm{T}_{1} 65.33, \mathrm{~T}_{2} 65.00, \mathrm{~T}_{3} 65.22, \mathrm{~T}_{4}$ 65.60 and $T_{5} 66.66^{\circ}$ brix for the glass jar stored at room temperature condition.

Effect on acidity: The data of effect on acidity is presented inTable 1 . The acidity significantly decreased with decrease in storage period irrespective of level of sugar and jiggery and storage period conditions. The acidity values after
60 days of storage were observed as $T_{1} 0.353, T_{2}$ $0.349, \mathrm{~T}_{3} 0.333, \mathrm{~T}_{4} 0.322$ and $\mathrm{T}_{5} 0.366$ for the sample stored in pet jar at room temperature conditions. The acidity values after 60 days of storage were observed as $T_{1} 0.348, T_{2} 0.360, T_{3}$ $0.350, T_{4} 0.333$ and $T_{5} 0.359$ for the sample stored in glass jar at room temperature conditions. The highest acidity value sample of $\mathrm{T}_{5} 0.366$ in pet jar and $T_{2} \quad 0.360$ in glass jar at room temperature conditions. The acidity values increase through by different sweetener and papaya ratio in the samples. Papaya fruits contain 6.5 to $13^{\circ}$ Brix of TSS in Pusa varieties (Ram, 1982) and $9.8^{\circ}$ Brix in loorg honey dew. The $\mathrm{pH}$ of papaya ranges between 5.0 to 5.51 and acidity (as percent anhydrous citric acid) $0.12 \%$ (Ahmad and Chaudhary, 1995).

Effect on pH: The result showed that the $\mathrm{pH}$ of sample increased with increase in storage periods at room temperature. The $\mathrm{pH}$ also increased with storage period irrespective of papaya and sweeteners ratio. The study also revealed that $\mathrm{pH}$ increased with increase in storage period at room temperature conditions. The data presented in Table 1 showed the effect of $\mathrm{pH}$ of the samples of different sweeteners ratio with papaya extract. The $\mathrm{pH}$ values after 60 days of storage were observed as $\mathrm{T}_{1} 4.55, \mathrm{~T}_{2} 4.45, \mathrm{~T}_{3} 4.77, \mathrm{~T}_{4} 4.80$ and $\mathrm{T}_{5} 4.75$ for the sample stored in pet jar at room temperature conditions. The $\mathrm{pH}$ values after 60 days of storage were observed as $T_{1} 4.55, T_{2} 4.75, T_{3} 4.70, T_{4} 4.85$ and $\mathrm{T}_{5} 4.76$ for the sample stored in glass jar at room temperature conditions. The highest $\mathrm{pH}$ value for the sample of $\mathrm{T}_{4} 4.80$ in pet jar and $\mathrm{T}_{4} 4.85$ in glass jar at room temperature conditions.

Effect on optical density: The data on optical density of leather made from different sweet proportion of sugar and jaggery is presented in Table1. It is clear that the optical density of samples increased with increase in storage periods at room temperature. The effect of compositions (sugar, jaggery and papaya extract pulp) and storage period were found significant. The combined effect of composition and storage periods were also significant. The highest optical density value $T_{4}$ 1.33 in pet jar and $\mathrm{T}_{5} 1.26$ in glass jar at room 
temperature. The increase in optical density indicated browning with advancement of storage periods, which could be ascribed to oxidation and development of non-enzymatic browning (an amino acid and reducing sugar reaction). This increase in optical density may be attributed to non-enzymatic browning which would have taken place during storage. Non-enzymatic maillard browning reaction may take place between nitrogenous compounds and sugar, nitrogenous compound and organic acids, and among organic acids themselves (Srivastava and Kumar, 2000).

\section{Effect on microbial growth (Total Plate count):} The experimental data represented in Table 2 were analyzed to see the effect of microbial growth of the samples of different sweeteners ratio with papaya during storage. The microbial growth of the samples pet jar were observed as $T_{1} 1.12 \times 10^{5} \mathrm{cfu} / \mathrm{ml}$, $\mathrm{T}_{2} \quad 1.11 \times 10^{5} \mathrm{cfu} / \mathrm{ml}, \quad \mathrm{T}_{3} \quad 1.12 \times 10^{5} \mathrm{cfu} / \mathrm{ml}, \quad \mathrm{T}_{4}$ $1.13 \times 10^{5} \mathrm{cfu} / \mathrm{ml}$ and $\mathrm{T}_{5} 1.12 \times 10^{5} \mathrm{cfu} / \mathrm{m}$ and the sample of glass jar $\mathrm{T}_{1} 1.09 \times 10^{5} \mathrm{cfu} / \mathrm{ml}, \quad \mathrm{T}_{2}$ $1.10 \times 10^{5} \mathrm{cfu} / \mathrm{ml}, \quad \mathrm{T}_{3} \quad 1.09 \times 10^{5} \mathrm{cfu} / \mathrm{ml}, \quad \mathrm{T}_{4}$ $1.11 \times 10^{5} \mathrm{cfu} / \mathrm{ml}$ and $\mathrm{T}_{5} 1.18 \times 10^{5} \mathrm{cfu} / \mathrm{m}$ at room temperature condition after 60 days. The study revealed that the microbial growth increased with increase of storage period. The highest microbial growths were observed as $\mathrm{T}_{4} 1.13 \times 10^{5} \mathrm{cfu} / \mathrm{ml}$ of pet jar and $\mathrm{T}_{5} 1.18 \times 10^{5} \mathrm{cfu} / \mathrm{ml}$ at room temperature conditions. Saravana and Manimeglai (2005) reported the microbial load as $1-2 \times 10^{6}$ bacteria, 1 $2 \times 10^{4}$ fungi and $1 \times 2 \times 10^{5}$ per gram yeast in whey based papaya juice blended RTS up to 90 days of storage in refrigerator condition, which was considered safe for consumption.

Overall acceptability: Sensory quality of papaya leather attributes viz. colour, flavour, texture, taste and overall acceptability were evaluated. Nine points hedonic rating test method as recommended by Joshi (2006) was used for the purpose of sensory evaluation. This test measures the consumer's acceptability. In general significant decrement in overall acceptability score was observed for all samples with few exceptions during storage showed in Table $3 \& 4$. Most of the samples were not accepted by the panelist after 60 days. The highest colour score of the sample $T_{3}$ (7.2) in pet jar and the decreased score of the colour effect by the jaggery ratio in the papaya leather. The highest flavour score of the sample $T_{1}(7.3)$ in glass jar. The highest texture and taste score of the sample $\mathrm{T}_{2}(7.1)$ and $T_{3}$ (7.1). All the sensory score decreased on the effect of storage period and the superior sample of the glass jar samples. The highest overall acceptability of the sample of $\mathrm{T}_{1}$ (7.1) in glass jar and the highest overall acceptability of the sample of $\mathrm{T}_{1}$ (6.8) in pet jar at room temperature after storage of 60 days.

\section{Conclusion}

The effect of sugar and jaggery on the quality characteristics of papaya leather during room temperature found superior sample of the glass jar because after 60 days. The moisture content of the samples decreases and The TSS of papaya leather increased slightly with increase of sugar and jaggery ratio as well as increase in the storage period. The $\mathrm{pH}$ of samples increased and acidity decreased either with decrease in the ratio of the sugar ratio during storage period. The optical density increased with the jaggery browning reaction in the presence of the oxidase caused by trapped or residual oxygen in the glass of the samples storage at room temperature. The microbial growth increased during period irrespective of sugar and jaggery ratio in storage conditions. 
Table 1: Effect on Physico-chemical, microbial growth and overall acceptability of papaya leather in different packaging at room temperature during storage.

\begin{tabular}{|c|c|c|c|c|c|c|c|c|c|c|c|}
\hline \multicolumn{12}{|c|}{ Packaging materials } \\
\hline \multicolumn{6}{|c|}{ PET JAR } & \multicolumn{6}{|c|}{ GLASS JAR } \\
\hline \multicolumn{12}{|c|}{ MOISTURE CONTENT \% } \\
\hline Days & $\mathbf{T}_{1}$ & $\mathbf{T}_{2}$ & $\mathbf{T}_{3}$ & $\mathbf{T}_{4}$ & $\mathbf{T}_{5}$ & $\mathbf{T}_{1}$ & $\mathbf{T}_{2}$ & $\mathbf{T}$ & & $\mathbf{T}_{4}$ & $\mathbf{T}_{5}$ \\
\hline $\mathbf{0}$ & 19.0 & 18.8 & 18.9 & 19.0 & 19.1 & 19.2 & 18.8 & 18 & & 19.1 & 19.0 \\
\hline 15 & 18.5 & 18.0 & 18.3 & 18.6 & 18.8 & 18.4 & 18.3 & 18 & & 18.6 & 18.8 \\
\hline 30 & 18.0 & 17.0 & 17.5 & 17.9 & 17.5 & 18.0 & 17.8 & 17 & & 18.0 & 17.9 \\
\hline 45 & 17.3 & 16.0 & 17.7 & 17.5 & 17.1 & 17.2 & 17.0 & 16 & & 17.5 & 17.1 \\
\hline 60 & 16.9 & 15.5 & 16.7 & 17.0 & 16.4 & 16.7 & 16.3 & 16 & & 17.0 & 16.1 \\
\hline \multicolumn{12}{|c|}{ TSS } \\
\hline Days & T1 & T2 & T3 & T4 & T5 & T1 & T2 & $\mathbf{T}$ & & T4 & T5 \\
\hline $\mathbf{0}$ & 63.0 & 63.0 & 63.75 & 63.75 & 64.0 & 63.0 & 63.0 & 63 & & 63.75 & 64.0 \\
\hline 15 & 63.50 & 63.61 & 63.98 & 63.98 & 64.29 & 63.40 & 63.5 & 63 & & 63.99 & 64.75 \\
\hline 30 & 64.10 & 64.20 & 63.40 & 70.25 & 65.10 & 64.25 & 64.1 & 64 & & 64.22 & 65.11 \\
\hline 45 & 64.99 & 65.10 & 64.00 & 70.95 & 65.99 & 64.99 & 64.8 & 64 & & 64.90 & 65.88 \\
\hline 60 & 65.33 & 65.99 & 65.15 & 71.15 & 66.66 & 65.33 & 65.0 & 65 & & 65.60 & 66.66 \\
\hline \multicolumn{12}{|c|}{ ACIDITY \% } \\
\hline Days & $\mathbf{T}_{1}$ & $\mathbf{T}_{2}$ & $\mathbf{T}_{3}$ & $\mathbf{T}_{4}$ & $\mathbf{T}_{5}$ & $\mathbf{T}_{1}$ & $\mathbf{T}_{2}$ & $T$ & & $\mathbf{T}_{4}$ & $\mathbf{T}_{5}$ \\
\hline $\mathbf{0}$ & 0.453 & 0.447 & 0.451 & 0.455 & 0.477 & 0.432 & 0.44 & 0.4 & & 0.439 & 0.467 \\
\hline 15 & 0.432 & 0.418 & 0.427 & 0.438 & 0.444 & 0.400 & 0.41 & 0.4 & & 0.400 & 0.422 \\
\hline 30 & 0.391 & 0.389 & 0.394 & 0.397 & 0.399 & 0.380 & 0.38 & 0.3 & & 0.369 & 0.389 \\
\hline 45 & 0.377 & 0.368 & 0.368 & 0.348 & 0.375 & 0.367 & 0.38 & 0.3 & & 0.340 & 0.370 \\
\hline 60 & 0.353 & 0.349 & 0.333 & 0.322 & 0.366 & 0.348 & 0.36 & 0.3 & & 0.333 & 0.359 \\
\hline & \multicolumn{11}{|c|}{ pH } \\
\hline Days & $\mathbf{T}_{1}$ & $\mathbf{T}_{2}$ & $\mathbf{T}_{3}$ & $\mathbf{T}_{4}$ & $\mathbf{T}_{5}$ & $\mathbf{T}_{1}$ & $\mathbf{T}_{2}$ & T & & $\mathbf{T}_{4}$ & $\mathbf{T}_{5}$ \\
\hline $\mathbf{0}$ & 3.60 & 3.68 & 3.78 & 3.99 & 3.77 & 3.60 & 3.68 & 3. & & 3.99 & 3.77 \\
\hline 15 & 3.70 & 3.80 & 3.90 & 4.12 & 4.00 & 3.69 & 3.79 & 3. & & 4.18 & 4.10 \\
\hline 30 & 3.99 & 4.22 & 4.33 & 4.25 & 4.37 & 3.99 & 3.85 & 4. & & 4.38 & 4.30 \\
\hline 45 & 4.30 & 4.38 & 4.55 & 4.44 & 4.50 & 4.28 & 4.35 & 4. & & 4.55 & 4.62 \\
\hline 60 & 4.55 & 4.45 & 4.77 & 4.80 & 4.75 & 4.55 & 4.75 & 4. & & 4.85 & 4.76 \\
\hline \multicolumn{12}{|c|}{ OPTICAL DENSITY } \\
\hline Days & $\mathbf{T}_{1}$ & $\mathbf{T}_{2}$ & $T_{3}$ & $\mathbf{T}_{4}$ & $T_{5}$ & $T_{1}$ & $\mathbf{T}_{2}$ & $T_{3}$ & $T_{4}$ & & $T_{5}$ \\
\hline 0 & 0.40 & 0.52 & 0.58 & 0.62 & 0.66 & 0.40 & 0.52 & 0.58 & 0.62 & & 0.66 \\
\hline 15 & 0.55 & 0.66 & 0.78 & 0.75 & 0.75 & 0.50 & 0.60 & 0.66 & 0.78 & & 0.77 \\
\hline 30 & 0.77 & 0.82 & 0.89 & 0.88 & 0.90 & 0.73 & 0.70 & 0.71 & 0.83 & & 0.88 \\
\hline 45 & 0.99 & 1.00 & 1.08 & 1.04 & 1.11 & 0.90 & 0.97 & 0.98 & 0.99 & & 0.96 \\
\hline 60 & 1.19 & 1.29 & 1.26 & 1.33 & 1.27 & 1.21 & 1.11 & 1.19 & 1.22 & & 1.26 \\
\hline
\end{tabular}


Table 2: Effect on microbial growth $\left(\times 10^{5} \mathrm{cfu} / \mathrm{ml}\right)$ of papaya leather in different packaging at room temperature

\begin{tabular}{|c|c|c|c|c|c|c|c|c|c|c|}
\hline \multirow{2}{*}{ Days } & \multicolumn{4}{|c|}{ PET JAR } & \multicolumn{5}{|c|}{ GLASS JAR } \\
\cline { 2 - 11 } & $\mathbf{T}_{\mathbf{1}}$ & $\mathbf{T}_{\mathbf{2}}$ & $\mathbf{T}_{\mathbf{3}}$ & $\mathbf{T}_{\mathbf{4}}$ & $\mathbf{T}_{\mathbf{5}}$ & $\mathbf{T}_{\mathbf{1}}$ & $\mathbf{T}_{\mathbf{2}}$ & $\mathbf{T}_{\mathbf{3}}$ & $\mathbf{T}_{\mathbf{4}}$ & $\mathbf{T}_{\mathbf{5}}$ \\
\hline $\mathbf{0}$ & $\mathrm{ND}$ & $\mathrm{ND}$ & $\mathrm{ND}$ & $\mathrm{ND}$ & $\mathrm{ND}$ & $\mathrm{ND}$ & $\mathrm{ND}$ & $\mathrm{ND}$ & $\mathrm{ND}$ & $\mathrm{ND}$ \\
\hline $\mathbf{1 5}$ & 1.02 & 1.03 & 1.02 & 1.03 & 1.02 & 1.02 & 1.03 & 1.02 & 1.03 & 1.05 \\
\hline $\mathbf{3 0}$ & 1.05 & 1.06 & 1.07 & 1.07 & 1.06 & 1.04 & 1.04 & 1.03 & 1.05 & 1.08 \\
\hline $\mathbf{4 5}$ & 1.08 & 1.08 & 1.09 & 1.09 & 1.09 & 1.06 & 1.05 & 1.05 & 1.07 & 1.13 \\
\hline $\mathbf{6 0}$ & 1.12 & 1.11 & 1.12 & 1.13 & 1.12 & 1.09 & 1.10 & 1.09 & 1.11 & 1.18 \\
\hline
\end{tabular}

Table 3: Effect on sensory attributes (colour, flavour, texture, taste and overall acceptability) of the fresh papaya leather at room temperature

\begin{tabular}{|c|c|c|c|c|c|c|c|c|c|c|}
\hline & \multicolumn{5}{|c|}{ PET JAR } & \multicolumn{5}{c|}{ GLASS JAR } \\
\hline Samples & Colour & Flavour & Texture & Taste & O. A. & Colour & Flavour & Texture & Taste & O.A. \\
\hline $\mathbf{T}_{\mathbf{1}}$ & 8.5 & 7.9 & 7.3 & 7.9 & 7.9 & 8.4 & 7.8 & 7.4 & 7.9 & 7.8 \\
\hline $\mathbf{T}_{\mathbf{2}}$ & 8.5 & 7.7 & 7.2 & 7.7 & 7.7 & 8.3 & 7.8 & 7.3 & 7.7 & 7.7 \\
\hline $\mathbf{T}_{\mathbf{3}}$ & 8.8 & 6.9 & 7.4 & 8.1 & 7.8 & 8.5 & 6.9 & 7.7 & 8.3 & 7.8 \\
\hline $\mathbf{T}_{\mathbf{4}}$ & 8.2 & 6.8 & 7.2 & 7.3 & 7.3 & 8.4 & 7.1 & 7.5 & 7.4 & 7.6 \\
\hline $\mathbf{T}_{\mathbf{5}}$ & 8.4 & 7.7 & 7.0 & 8.1 & 7.8 & 8.4 & 7.7 & 7.2 & 8.2 & 7.8 \\
\hline
\end{tabular}

Table 4: Effect on sensory attributes (colour, flavour, texture, taste and overall acceptability) of papaya leather at room temperature conditions after 60 days

\begin{tabular}{|c|c|c|c|c|c|c|c|c|c|c|}
\hline & \multicolumn{9}{|c|}{ PET JAR } & \multicolumn{5}{c|}{ GLASS JAR } \\
\hline Samples & Colour & Flavour & Texture & Taste & O. A. & Colour & Flavour & Texture & Taste & O. A. \\
\hline $\mathbf{T}_{\mathbf{1}}$ & 7.0 & 6.9 & 6.7 & 6.9 & 6.8 & 7.1 & 7.3 & 7.0 & 6.9 & 7.1 \\
\hline $\mathbf{T}_{\mathbf{2}}$ & 6.9 & 6.7 & 6.5 & 6.7 & 6.7 & 6.9 & 7.0 & 7.1 & 7.0 & 6.9 \\
\hline $\mathbf{T}_{\mathbf{3}}$ & 7.2 & 6.5 & 6.3 & 7.1 & 6.5 & 6.7 & 6.8 & 6.9 & 6.7 & 6.7 \\
\hline $\mathbf{T}_{\mathbf{4}}$ & 6.5 & 6.4 & 6.1 & 6.3 & 6.3 & 6.4 & 6.5 & 6.7 & 6.5 & 6.5 \\
\hline $\mathbf{T}_{\mathbf{5}}$ & 6.3 & 6.2 & 6.0 & 6.1 & 6.1 & 6.3 & 6.2 & 6.5 & 6.4 & 6.3 \\
\hline
\end{tabular}

$\mathrm{ND}=$ Not Detected

$\mathrm{T}_{1}=$ Papaya with sugar $\left(\mathrm{P}_{1 \mathrm{~kg}}+\mathrm{S}_{650 \mathrm{gm}}\right)$

$\mathrm{T}_{3}=$ Papaya with jaggery $\left(\mathrm{P}_{1 \mathrm{~kg}}+\mathrm{J}_{650 \mathrm{gm}}\right)$

$\mathrm{T}_{5}=$ Papaya with sugar and jaggery $\left(\mathrm{P}_{1 \mathrm{~kg}}+\mathrm{S}_{500 \mathrm{gm}}+\mathrm{J}_{500 \mathrm{gm}}\right)$

\section{References}

1. Ahmad, J. and Chaudhary, D.R. (1995). Osmotic dehydration of papaya. Indian Food Packer.49(5): 5- 9.

$$
\begin{aligned}
& \mathrm{T}_{2}=\text { Papaya with sugar }\left(\mathrm{P}_{1 \mathrm{~kg}}+\mathrm{S}_{450 \mathrm{gm}}\right) \\
& \mathrm{T}_{4}=\text { Papaya with jaggery }\left(\mathrm{P}_{1 \mathrm{~kg}}+\mathrm{J}_{450 \mathrm{gm}}\right)
\end{aligned}
$$

2. Chan, H. T. Jr., and Cavaletto, C. G., (1978). Dehydration and storage stability of papaya leather. J. Food Sci. 43: 1723- 1725.

3. Harrigan, C. and McCance, P. (1966). Laboratory methods in microbiology, Academic Press, New York. 
4. Joshi, V. K. (2006). Sensory science: Principles and application in food evaluation. Agrotech Publish Academy, Jaipur (India).

5. Mehta, V. and Bajaj, S. (1969). Effect of storage and methods of preservation on the physic-chemical characteristics of citrus juices. Indian Food Packer. 37: 42- 51.

6. Pandey, A. K. (2004). Study about the storage stability of guava beverages. Prog. Hort. 36 (1): 142- 145.

7. Purseglove, J.W. (1968). Tropical Crops. Dicotyledons. Vol. 2. Wiley, New York.

8. Ram B. (1982). Studies on processing and preservation of aonla fruit beverage M. Sc. Thesis, N.D.U.A. and T., Kumarganj, Faizabad.

9. Saravana, K. and Manimegalai, G. (2005). Studies on storage stability whey based papaya juice blended RTS beverage. J. Food Sci. Technol. 42(2): 185-188.

10. Selvaraj, Y., Pal, D. K., Subramanyma, M. D. and lyer, C. P. A. (1982). Fruit set and development pattern of fruit of five papaya varieties. Indian J. Hort. 39: 50-56.

11. Singh, I. J., Singh, H. K. and Chopra, C. S. (2004). Studies on storage stability of Bahal products. Bev. Food World. 31:29- 30.

12. Srivastava, R. P. and Kumar, S. (1994). Fruit and vegetables preservation (Principal and Facts). International Book Distributing Company, Charbag, Lucknow

13. Srivastava, R. P. and Kumar, S. (2000). Fruit and vegetables preservation (Principal and Facts). International Book Distributing Company, Charbag, Lucknow 